\title{
A Survey of Physiotherapists on Physical Activity Promotion in Northern Nigeria
}

\author{
Oyeyemi, A.Y., ${ }^{1}$ Yunus, R. H., ${ }^{2}$ Oyeyemi, A.L., ${ }^{1}$ Usman, Z. $^{3}$ \\ ${ }^{1}$ Department of Medical Rehabilitation (Physiotherapy), College of Medical Sciences, University of Maiduguri, \\ Maiduguri, Nigeria \\ ${ }^{2}$ Department of Physiotherapy, Aminu Kano Teaching Hospital, Kano, Nigeria \\ ${ }^{3}$ College of Health Sciences, Federal University Dutse Teaching Hospital, Dutse, Jigawa State
}

Correspondence

Adetoyeje Y. Oyeyemi, Department of Medical Rehabilitation (Physiotherapy), College of Medical Sciences, University of Maiduguri, Maiduguri, Nigeria•Email: adeoyeyemi@aol.com; alaoyeyemi@yahoo.com

\begin{abstract}
Tackling the menace of non-communicable diseases (NCDs) through the promotion of population participation in health enhancing physical activities requires the engagement of healthcare experts, such as physiotherapists, to make necessary assessments and individualized recommendation.

The aim of this study was to determine the knowledge of physical activity message, role perception and counselling practice, and the feasibility of, and barriers to physical activity promotion among physiotherapists in Northern Nigeria.

Physiotherapists in seven hospitals in Northern Nigeria ( $N=94)$ were surveyed using a questionnaire that elicited information on socio-demographic characteristics and the participants also completed a Physical Activity Promotion Questionnaire which elicited responses on knowledge of physical activity message, feasibility of physical activity promotion, and barriers to physical activity promotion.

Overall, the physiotherapists in this study reported good knowledge of physical activity promotion, perceived physical activity promotion as their role, and also reported minimal or little barrier to physical activity promotion. The physiotherapists also believed promoting physical activity was feasible for them.

These findings suggest that physiotherapists in Northern Nigerian have a good disposition towards promoting a physically active lifestyle among their patients and clients and they could play an important public health role in the prevention and control of NCDs in Nigeria.
\end{abstract}

Keywords: Physical activity, physical activity promotion, physiotherapists, disposition, active lifestyle

\section{INTRODUCTION}

Physical activity is defined as any bodily movement produced by the contraction of striated muscles that substantially increases energy expenditure (United States Department of Health and Human Services [USDHHS], 2004; World Health Organization [WHO], 2007). The term is often used interchangeably with exercise which is a subset of physical activity prescribed with improvement in cardiorespiratory fitness in view. Generally, participation in any type or amount of physical activity in leisure time can provide important health benefits as compared to a sedentary lifestyle (USDHHS, 2000; USDHHS, 2004; WHO, 2009). A physically active lifestyle has been shown to significantly reduce the risk of developing cardiovascular disease, obesity, type- 2 diabetes, several forms of cancer, depression (Haskell et al, 2007), osteoporosis, and premature death (Katzmarzyk et al, 2009). Regular physical activity also decreases all-cause mortality risk by 20 to $30 \%$ 
compared with insufficient activity (Lee and Skerrett, 2001).

Due to the rapidly rising prevalence of chronic noncommunicable diseases in developing countries, it is urgent that physical activity promotion is prioritized in sub-Saharan Africa (Oyeyemi et al, 2012). Worldwide, environmental and policy interventions for physical activity promotion have been instituted in many countries because they can influence large groups and bring about population-wide changes (WHO, 2007; Heath et al, 2012; Sallis and Owen, 2015). However, personnel with requisite knowledge and expertise are required to assist in policy development and programme implementation to effect changes to improve behaviour on physical activity.

Physical therapists are believed to have adequate knowledge and skills to undertake a role in physical activity promotion and their practice setting is deemed a feasible avenue for promoting an active lifestyle. A physical activity counsellor can effectively promote the improvement of patients' daily physical activity levels in a series of one-onone counselling sessions (van der Ploeg et al, 2007). Although the role of physiotherapists in physical activity promotion has been documented through studies in the United States (Shumpert et al, 2009), England (Cooper et al, 2000), Germany (Verhagen and Engbers, 2009), and Australia (Shirley et al, 2010), it has been hypothesized that their confidence in prescribing non-treatment physical activity programmes is the best predictor of physical activity prescription (Shirley et al, 2010).

Physiotherapists are involved in the primary prevention of non-communicable diseases or risk reduction for these diseases and are also more likely than other health professionals to be asked for advise on physical activity and exercise. The disposition of physiotherapy professionals to promoting physical activity is an indirect indication of their knowledge and understanding of the health-enhancing benefits of physical activity and their role in promoting physical activity (Shirley et al, 2010). It is therefore important to ascertain their degree of awareness on physical activity guidelines and their disposition to promoting healthenhancing behaviour among their clients and patients. Empirical data on physiotherapists' disposition to promoting physical activity have implications for identifying any intervention and curriculum content inclusion needs towards enhancing the promotion of physical activity prescription by physiotherapists.
Presently, there is a paucity of data on the views of Nigerian physiotherapists about their potential role in promoting physical activity. This study was aimed at investigating the knowledge, confidence, role perception, barriers, feasibility and counselling practice of physiotherapists practicing in Northern Nigeria regarding the promotion of physical activity for health among their patients and clients, and also to determine the sociodemographic characteristics that influence their disposition to physical activity promotion. It was hypothesized that there would be no significant relationship between knowledge, confidence, role perception, barriers and feasibility of physical activity promotion among physiotherapists with different socio-demographic characteristics.

\section{MATERIALS AND METHODS}

\section{Participants}

Ninety-four (94) male and female physiotherapists working in some selected hospitals in the north-Eastern and northwestern parts of the country participated in this study. The hospitals include University of Maiduguri Teaching Hospital and Maiduguri Specialist Hospital in Maiduguri, Borno State; Murtala Mohammed Specialist Hospital, Muhammad Abdullahi Wase General Hospital, Aminu Kano Teaching Hospital, and National Orthopaedic Hospital Dala, in Kano, Kano State; Federal Medical Centre in Gombe, Gombe State; and Federal Medical Centre, Birnin Kudu, Jigawa State. A sample of convenience was used to recruit physiotherapists that were available and willing to participate in the cross-sectional survey study.

\section{Materials}

Participants were surveyed using a questionnaire, the first part of which elicited socio-demographic information such as age, gender, marital status, rank, area of specialty, educational level, and years of work. The second part consisted of the Physical Activity Disposition Questionnaire, an instrument that was adapted from a previous survey questionnaire in a study by Mark et al (1999) and previously designed and used to assess physical activity promotion among primary care physicians (van der Ploeg, 2007). The adaptations made to the questionnaire were minor and only aimed to make the questionnaire relevant for physiotherapists. The adapted questionnaire elicited responses in the domains on knowledge on physical activity promotion, perceived barriers to physical activity 
promotion and feasibility of physical activity promotion strategies.

For the knowledge items, the possible response to items on the scale ranged from a minimum score of 1 (strongly disagree) to 5 (strongly agree). For the barrier items the possible score ranged from 1 (never) to 5 (very often), while for the feasibility items the score ranged from 5 (highly feasible) to 1 (totally unfeasible). Each of the items on each domain also had a summative score. The knowledge items had a maximum possible score of 30 and minimum possible score of 6 . For the barrier items, the maximum and minimum possible scores were 30 and 6 respectively, whereas for the feasibility items, the maximum and minimum possible scores were 20 and 4 respectively. For the knowledge and feasibility items, the higher the score the more knowledgeable about physical activity promotion and the better the participant's perceived feasibility of physical activity promotion.

However, for the barrier items, the higher the score, the more the perceived barrier to physical activity promotion. One item in the knowledge of physical activity domain was "Exercise that is good for health must make you pant". This item was considered negatively worded and therefore a strongly disagree response was most accurate and was scored 5, while a strongly agree response was incorrect and was assigned 1. An example of a positively worded item is "Several short walks of 10 minutes each on most days is better than one round of golf per week for good health". The most accurate response was strongly agree and was scored 5 while the least accurate response was strongly disagree and was scored 1 .

An example of a barrier item is: 'How often does lack of time prevent you from promoting physical activity lifestyle in your patients? On feasibility items, one example is: 'Separate one-on-one is a kind of physical activity promotion that is feasible to deliver to patients'. The questionnaire was administered to 15 physiotherapists in University of Maiduguri Teaching Hospital twice within an interval of two weeks. A reliability coefficient (Spearman's rho) of 0.98 indicates that the instrument has good reliability. The physiotherapists were also asked to estimate the number of patients they had encouraged to lead a more physically active lifestyle in the previous month.

\section{Procedure}

Prior to commencement of the study, ethical approval was sought and obtained from the Research and Ethical
Committee of the University of Maiduguri Teaching Hospital. The study protocol was fully explained to each participant and informed consent was signed before they were allowed into the study. Participants in Maiduguri were approached at the hospital while those outside Maiduguri were reached through agents who were physiotherapists based in the selected hospitals. Completed questionnaires were returned in sealed envelopes directly to the investigator (RHY) or via postage through agents.

\section{Data Analyses}

Descriptive statistics of mean, standard deviation, frequency and percentage were used to summarize the participants' scores on knowledge, role perception, confidence, barriers, feasibility, and composite physical activity promotion, as well as their socio-demographic information as appropriate. The relationships among knowledge, confidence, role perception, barriers to and feasibility of physical activity promotion were explored using Spearman's correlation statistics. Chi-square $(\chi 2)$ was used to determine differences in participants' knowledge level, confidence, role perception, barriers and feasibility of physiotherapists by socio-demographic subgroups such as gender, with statistical significance set at $P<0.05$

\section{RESULTS}

\section{Socio-demographic Characteristics of the Participants}

A total of 94 participants across hospital settings in Northern Nigeria were given the questionnaire and all were returned completed and usable. More males $(64.9 \%, \mathrm{n}=61)$ than females $(35.1 \%, \mathrm{n}=33)$ participated in this study. The majority of the participants $(64.9 \%, \mathrm{n}=61)$ were in the age group of $\leq 30$ years, while only $4(4.3 \%)$ were between the age range of $45-54$ years. Thirty-eight $(25.6 \%)$ participants were interns while only $4(4.2 \%)$ were chief physiotherapists. Forty-two participants $(n=42,44.7 \%)$ were single and $52(55.3 \%)$ were married. The majority of the participants $(n=80,85.1 \%)$ had a Bachelor's degree and none had a $\mathrm{PhD}$ degree (a reflection that the participants were primarily selected from the clinics and not the academia). The average number of patients provided with care per week was 11 and the average number of hours worked per week was 32. Detailed information on the socio-demographic characteristics of the participants is shown in table 1 . 
Table 1. Socio-demographic characteristics of the participants

\begin{tabular}{lcc}
\hline Characteristics & Frequency & Percentage \\
\hline $\begin{array}{l}\text { Age group (years) } \\
\quad 30\end{array}$ & 61 & 64.9 \\
$31-44$ & 29 & 30.9 \\
$\quad 45$ or $>$ & 4 & 4.2 \\
Gender & & \\
$\quad$ Male & 61 & 64.9 \\
$\quad$ Female & 33 & 35.1 \\
Marital Status & & \\
$\quad$ Single & 42 & 44.7 \\
$\quad$ Married & 52 & 55.3 \\
Rank & & \\
$\quad$ Intern and Physiotherapist & 63 & 67.0 \\
$\quad$ Senior & 11 & 11.7 \\
$\quad$ Principal and Chief & 20 & 21.3 \\
Highest Qualification & & \\
$\quad$ Bachelor's degree & 80 & 85.1 \\
$\quad$ Master's degree & 14 & 14.9 \\
\hline
\end{tabular}

\section{Knowledge of Physical Activity Promotion Message}

When participants were asked whether half an hour of walking on most days is all the exercise that is needed for good health, 19 (20.2\%) responded they strongly agreed, $42(44.7 \%)$ agreed, $8(8.5 \%)$ were not sure, $22(23.4 \%)$ disagreed and $3(3.2 \%)$ strongly disagreed. Only $6(6.4 \%)$ strongly agreed and $21(22.3 \%)$ agreed that 'exercise that is good for health must make you pant', but 19(20.2) were not sure, 35 (37.2\%) disagreed and 13 (13.8\%) strongly disagreed with the statement. Only $5(5.4 \%)$ participants either disagreed or were not sure that physiotherapists should be physically active as role models to their patients, while $20(21.3 \%)$ agreed and $69(73.4 \%)$ strongly agreed (table 2).

Participants mean summative score on knowledge was $37.1 \pm 4.7$ out of a possible score of 45 . Participants' composite physical activity promotion disposition score was dichotomized into satisfactory and unsatisfactory using $60 \%$ correct score as the threshold. An overwhelming majority $(87 \%)$ of the physiotherapists had satisfactory disposition to promoting physical activity among patients. The above results indicate that overall, the participants have good knowledge of physical activity promotion message.

\section{Barriers to Physical Activity Promotion}

When participants were asked how often lack of time prevented them from promoting physical activity 16 $(17.0 \%)$ responded 'never', 21 (21.3\%) responded 'rarely',
$44(46.8 \%)$ responded 'sometimes', $10(10.6 \%)$ responded 'often' and only $4(4.3 \%)$ responded 'very often'. When asked how often lack of counselling skills prevented them from promoting physical activity, $48(51.1 \%)$ responded 'never', 19 (20.2\%) responded 'rarely', 19 (20.2\%) responded 'sometimes' and $8(8.5 \%)$ responded often (table 3 ). The mean score on barriers was $12.9 \pm 4.5$ out of a possible score of 30 indicating that physiotherapists sometimes experienced some perceived barriers to physical activity promotion.

\section{Feasibility of Physical Activity Promotion}

When participants were asked whether separate one-on-one consultation as a kind of physical activity promotion would be feasible for them to deliver to patients, 31 (33.0\%) stated this would be highly feasible to them, 35 (37.2\%) responded that it would be feasible, $19(21.2 \%)$ were not sure it would be feasible and $9(9.6 \%)$ believed it was not really feasible for them. Group sessions would be highly feasible to $37(39.4 \%)$ participants, somewhat feasible for $34(36.2 \%)$ while it was either not really feasible or totally unfeasible for $12(12.8 \%)$ of the participants (see table 4 ). The mean feasibility score was $15.8+2.8$ out of a possible score of 20 indicating that participants considered overall promotion of physical activity feasible for them.

\section{Differences and Relationship}

The data were analysed to ascertain whether there were differences in disposition to promoting physical activity among the physiotherapists by socio-demographic characteristics. The result shows no significant difference in knowledge, barriers or feasibility of physical activity promotion by gender or by years of service. Analysis of the dichotomized data also shows that there was no significant difference in physical activity promotion disposition by gender $(\chi 2=0.254, P$-value $=0.614)$ or by years of service $(\chi 2=0.552, P$-value $=0.458)$. A significant but tenuous correlation was observed between years of working experience and feasibility $(\mathrm{r}=-0.29, P=0.0045)$, but no correlation was observed between years of working experience on the one hand, and knowledge or barriers on the other hand. No significant relationship was found between knowledge and feasibility $(\mathrm{r}=0.059, P=0.570)$ or between knowledge and barriers. However, a negative but significant correlation was found between barriers and feasibility $(\mathrm{r}=-0.233, P=0.024)$. 
Oyeyemi, Yunus, Oyeyemi, Usman

Table 2. Knowledge of physical activity message

\begin{tabular}{|c|c|c|c|c|c|}
\hline Statement & $\begin{array}{c}\mathrm{SA} \\
\mathrm{n}(\%)\end{array}$ & $\begin{array}{c}\mathrm{A} \\
\mathrm{n}(\%)\end{array}$ & $\begin{array}{c}\mathrm{NS} \\
\mathrm{n}(\%)\end{array}$ & $\begin{array}{c}\mathrm{DA} \\
\mathrm{n}(\%)\end{array}$ & $\begin{array}{l}\mathrm{SD} \\
\mathrm{n}(\%)\end{array}$ \\
\hline $\begin{array}{l}\text { Taking the stairs at work and generally being more active each day is } \\
\text { enough physical activity to improve health }\end{array}$ & $18(19.1)$ & $53(56.4)$ & $7(7.4)$ & $13(13.8)$ & $3(3.2)$ \\
\hline $\begin{array}{l}\text { Half an hour of walking on most days is all the exercise that is needed } \\
\text { for good health }\end{array}$ & $19(20.2)$ & $42(44.7)$ & $8(8.5)$ & $22(23.4)$ & $3(3.2)$ \\
\hline Exercise that is good for health must make you pant & $6(6.4)$ & $21(22.3)$ & $19(20.2)$ & $35(37.2)$ & $13(13.8)$ \\
\hline $\begin{array}{l}\text { Several short walks of } 10 \text { minutes each on most days is better than one } \\
\text { round of golf per week for good health }\end{array}$ & $19(20.0)$ & $46(48.9)$ & $17(18.1)$ & $9(9.6)$ & $3(3.2)$ \\
\hline $\begin{array}{l}\text { Discussing the benefits of a physically active lifestyle with patients is } \\
\text { part of the physiotherapist's role }\end{array}$ & $63(67.0)$ & $23(24.5)$ & $5(5.3)$ & $3(3.2)$ & \\
\hline $\begin{array}{l}\text { Suggesting to patients ways to increase daily physical activity is part } \\
\text { of physiotherapist's role }\end{array}$ & $60(6.38)$ & $30(31.9)$ & $2(2.1)$ & $2(2.1)$ & \\
\hline $\begin{array}{l}\text { I feel confident in giving general advice to patients on a physically } \\
\text { active lifestyle }\end{array}$ & $63(67.0)$ & $24(25.5)$ & $4(4.3)$ & $2(2.1)$ & $1(1.1)$ \\
\hline I feel confident in suggesting specific activity programme for patients & $57(60.6)$ & $25(26.6)$ & $9(9.6)$ & $2(2.1)$ & $1(1.1)$ \\
\hline $\begin{array}{l}\text { Physiotherapists should be physically active as role models to their } \\
\text { patients }\end{array}$ & $69(73.4)$ & $20(21.3)$ & $1(1.1)$ & $4(4.3)$ & \\
\hline
\end{tabular}

$\mathrm{SA}=$ Strongly Agree; $\mathrm{A}=$ Agree; NS = Not Sure; DA Disagree; SD = Strongly Disagree

Table 3. Barriers to physical activity promotion

\begin{tabular}{|c|c|c|c|c|c|}
\hline \multirow{2}{*}{$\begin{array}{l}\text { How often does the following prevent you from promoting physical } \\
\text { activity }\end{array}$} & Never & Rarely & S & Often & VO \\
\hline & $\mathrm{n}(\%)$ & $\mathrm{n}(\%)$ & $\mathrm{n}(\%)$ & $\mathrm{n}(\%)$ & $\mathrm{n}(\%)$ \\
\hline Lack of time & $16(17.0)$ & $21(21.3)$ & $44(46.8)$ & $10(10.6)$ & $4(4.3)$ \\
\hline Lack of counselling skills & $48(51.1)$ & $19(20.2)$ & $19(20.2)$ & $8(8.5)$ & \\
\hline Lack of remuneration for promoting physical activity & $31(33.0)$ & $31(33.0)$ & $23(24.5)$ & $7(7.4)$ & $2(2.1)$ \\
\hline Lack of interest in promoting physical activity & $61(64.9)$ & $13(13.8)$ & $10(10.6)$ & $7(7.4)$ & $3(3.2)$ \\
\hline Feeling it will not change patient's behaviour & $48(51.1)$ & $22(23.4)$ & $15(16.0)$ & $8(8.5)$ & $1(1.1)$ \\
\hline Feeling it will not be beneficial to the patient & $62(66.0)$ & $14(14.9)$ & $14(14.9)$ & $3(3.2)$ & $1(1.1)$ \\
\hline
\end{tabular}

S denotes Sometimes; VO denotes Very Often

Table 4. Role confidence on physical activity promotion

\begin{tabular}{|c|c|c|c|c|c|}
\hline \multirow{2}{*}{$\begin{array}{l}\text { What kind of physical activity promotion would be } \\
\text { feasible for you to deliver to patents }\end{array}$} & $\mathrm{HF}$ & SF & NS & NRF & TU \\
\hline & $\mathrm{n}(\%)$ & $\mathrm{n}(\%)$ & $\mathrm{n}(\%)$ & $\mathrm{n}(\%)$ & $\mathrm{n}(\%)$ \\
\hline \multicolumn{6}{|l|}{ Brief counselling integrated into your regular } \\
\hline consultations & $54(57.4)$ & $28(29.8)$ & $7(7.4)$ & $4(4.3)$ & $1(1.1)$ \\
\hline Separate one-on-one consultation & $31(33.0)$ & $35(37.2)$ & $19(21.2)$ & $9(9.6)$ & \\
\hline Group sessions & $37(39.4)$ & $34(36.2)$ & $11(11.7)$ & $9(9.6)$ & $3(3.2)$ \\
\hline Distribution of resources (e.g. brochures) & $16(17.0)$ & $41(43.6)$ & $20(21.3)$ & $11(11.7)$ & $6(6.4)$ \\
\hline
\end{tabular}

HF denotes highly feasible; SF denotes somewhat feasible; NS denotes not sure; NRF denotes Not really feasible; TU denotes Totally Unfeasible

Physical Activity Recommendation, Encouragement and Physiotherapists' Lifestyle

When the participants were asked how often they had encouraged their patients to have a physically active lifestyle in the last month, $4.3 \%$ responded 'rarely' $(n=4)$, while $28(28.9 \%)$ responded they had encouraged 2-3 patients, $31(33.0 \%)$ responded they had encouraged 6-9 and another $31(33 \%)$ responded that they had encouraged
10 or more patients. When asked which exercise prescription the participants would recommend, $56.4 \%$ $(n=53)$ chose 30 minutes of moderately intense exercise or physical activity 4-5 times a week, while only $11.7 \%$ $(n=11)$ chose 15 minutes of moderately intense exercise or physical activity 5-6 times a week. This result indicates that the majority were aware of the optimal duration of physical activity per session and week. However, the overwhelming 
majority $(81.9 \%)$ responded 'No' when asked whether they were aware of any physical activity recommendation for Nigerian adults, while $18.1 \%(n=17)$ responded 'Yes'.

Furthermore, when asked how physically active they were compared to other Nigerians of the same sex and age, only $6(6.4 \%)$ responded they were much more active, 5 $(5.3 \%)$ responded they were slightly more active, 12 $(12.8 \%)$ responded about the same, $45(47.9 \%)$ responded they were slightly less active and $26(27.7 \%)$ were much less active. No significant differences on knowledge, barrier and feasibility were observed by gender, marital status or any of the demographic characteristics (not shown in table).

\section{DISCUSSION}

Physiotherapists are involved in the primary prevention of non-communicable diseases and are also involved in risk reduction for the diseases. These professionals are also more likely than other health personnel to be approached about physical fitness, physical activity and exercise. Physiotherapists in the present study have good knowledge of physical activity promotion message, had little barrier and believed promoting physical activity is feasible for them. This finding is similar to that of Shirley et al (2010) who observed that Australian physiotherapists had very good knowledge, had little barrier and believed promoting physical activity is feasible for them.

That many $(66 \%)$ of the physiotherapists in this study counseled between 6 to more than 10 patients in a months implies that they are involved in promoting physical activity among their patients. Similarly, Australian physiotherapists (54\%) counselled 10 or more patients to lead a more physically active life style (beyond therapeutic exercises) in a month (Shirley et al, 2010). That the overwhelming majority of the participants believe physiotherapists should be physically active as role models to their patients is an indication that they are aware of the need to stay in shape and 'practice what they preach'. The present study shows no significant difference between physical activity promotion disposition among physiotherapists by gender, consistent with that reported in another study of Australian physiotherapists (Shirley et al, 2010) who reported that both gender tend to promote physical activity equally.

In spite of the above findings, some results are not quite positive. Half of the participants either strongly agreed, agreed or were not sure that exercise that is good for health must make a client pant. Also many of them
(31\%) either strongly disagreed, disagreed or were not sure that several short walks of 10 minutes each on most days is better than one round of golf per week for good health. These results are an indication that knowledge and information on the intensity of exercise that could confer health benefits may not be optimal for half of the physiotherapists. This shows that some knowledge gap on physical activity guidelines for health exits that needs to be bridged among many of these physiotherapists.

Overall, the physiotherapists in the present study did not report any remarkable barrier to physical activity promotion and it can be argued that lack of time, rather than lack of remuneration, or lack of interest or counselling skills could prevent them from promoting physical activity. It is also apparent that integrating counselling into regular consultations would be most feasible for them than a separate one-on-one consultation as well as delivering resources such as brochures.

\section{Limitations of the Study}

One limitation of the present study is that the results obtained may be confounded by social desirability phenomenon (Anastasi, 1982) in which the participants may have responded to the items on physical activity promotion in ways that is perceived to be professionally desirable. The participants may therefore have exaggerated the perceived role, confidence, and feasibility of promoting a physically active lifestyle among physiotherapists. In addition, the absence of significant difference between variables as well as among variables may be attributed to the ceiling effect as a result of the high scores on the physical activity module by the physiotherapists and should be interpreted with caution.

\section{Conclusions}

Overall, physiotherapists in this study have good knowledge of physical activity promotion, although some knowledge gap on physical activity guideline for health exits among many of them. These physiotherapists perceived physical activity promotion as their role, and also reported minimal or little barrier to physical activity promotion. They also believed promoting physical activity was feasible to them. These findings suggest that physiotherapists in Northern Nigeria have good disposition towards promoting a physically active lifestyle among their patients and clients and they could play an important public health role in the prevention and control of NCDs in Nigeria. 


\section{References}

Anastasi A. 1982. Psychological Testing. 5th ed. New York, NY: Macmillan Publishing Co.

Cooper K., Clare A., Elizabeth H., Lynn J., Susan M. 2000. Robert Gordon University, Aberdeen: Enhancing Exercise and Physical Activity Promotion in Physiotherapy. NHS Grampian Physiotherapy Services: A Training Initiative, 30-45.

Haskell W.L., Lee I., Pate R.R. 2007. Physical activity and public health: Updated recommendations for adults from the American College of Sport Medicine and the American Heart Association. Medicine and Science in Sports Exercise 39: 1423-1434.

Heath G.W., Parra D.C., Sarmiento O.L., Andersen L.B., Owen L., Goenka S., Montes F., Brownson R.C., Lancet Physical Activity Series Working Group. 2012. Evidence-based intervention in physical activity: Lessons from around the world. Lancet 380(9838): 272-81.

Katzmarzyk P.T., Church T.S., Craig C.L., and Bouchard C. 2009. Sitting time and mortality from all causes, cardiovascular disease and cancer. Medicine and Science in Sport and Exercise 41(5): 988-1005.

Lee I.M., Skerrett P.J. 2001. Physical activity and all-cause mortality: What is the dose response relation? Medical Science Sports Exercise 33(6): 459 -471.

Mark A, Miners A, Bauman A, Walner F. 1999. Illawara Physical Activity Project. Wollongong: University of Wollongong.

Oyeyemi A.L., Babatunde O.A., James F.S., Oyeyemi A.Y. Ilse D.B. 2012. Perceived crime and traffic safety are related to physical activity among adults in Nigeria. Bio-Medical Central Public Health 12: 294.
Sallis J.F., Owen N. 2015. Ecological models of health behavior. In: Glanz K, Rimer B, Viswanath V, editors. Health Behavior: Theory, Research \& Practice, 5th edn. San Francisco: Jossey-Bass/Pfeiffer.

Shirley D., van der Ploeg H. P., Bauman A.E. 2010. Physical activity promotion in the physical therapy setting: Perspectives from practitioners and students. Physical Therapy 90: 13111322. doi: $10.2522 / \mathrm{ptj} .20090383$

Shumpert K.M., Hunt B., Hall, M.E. 2009. An Examination of the Role of Health Promotion in Physical Therapy.

United States Department of Health and Human Services. 2000. Healthy People 2010. Conference Edition 2: 20-25.

United States Department of Health and Human Services. 2004. Physical Activity and Health: A Report of the Surgeon General US Department of Health and Human services, Centre for Disease control and Prevention, National Centre for Chronic Disease, Prevention and Health Promotion.

van der Ploeg H.P., Smith B.J., Stubbs T. 2007. Physical activity promotion: Are GPs getting the message? Australian Family Physician 36: 871-874.

Verhagen E., Engbers L. 2009. The physical therapist's role in physical activity promotion. British Journal of Sports Medicine 43: 99-101.

WHO. 2007. Physical Activity: Global Strategy on Diet, Physical Activity and Health. http//www.who.int./dietphysicalactivity/pa/en/index-html assessed on 27/01/07 2:30 am

WHO. 2009. Global Health Risks: Mortality and burden of disease attributable to selected major risks. World Health Organization Health Reports 100(2): 126-131. 